\title{
Hemodynamics and bispectral index (BIS) of dogs anesthetized with midazolam and ketamine associated with medetomidine or dexmedetomidine and submitted to ovariohysterectomy ${ }^{1}$
}

\author{
Avaliação hemodinâmica e do índice bispectral (BIS) de cadelas anestesiadas com \\ midazolam e cetamina associados à medetomidina ou dexmedetomidina e submetidas a \\ ovário-salpingo-histerectomia
}

\author{
Fernando do Carmo Silva', Eduardo Hatschbach"I, Yuri Karaccas de Carvalho ${ }^{\mathrm{III}}$, Bruno Watanabe Minto ${ }^{\mathrm{I}}$, Flávio Massone ${ }^{\mathrm{IV}}$, \\ Paulo do Nascimento Junior` \\ ${ }^{\text {I}}$ Fellow PhD degree, Department of Anesthesiology, Botucatú Medical School, UNESP, Botucatú-SP, Brazil. \\ II PhD, Department of Anesthesiology, UNESP, Botucatú-SP, Brazil. \\ ${ }^{\text {III }}$ Master of Science, Department of Anesthesiology, Botucatú-SP, Brazil. \\ ${ }^{\text {IV }}$ Full Professor, Department of Veterinary Surgery and Anesthesiology, School of Veterinary Medicine and Animal Science, UNESP, Botucatú-SP, \\ Brazil. \\ ${ }^{\mathrm{v}}$ Associate Professor, Department of Anesthesiology, UNESP, Botucatú-SP, Brazil.
}

\begin{abstract}
Purpose: To evaluate hemodynamics and bispectral index (BIS) in bitches anesthetized with ketamine and midazolam in combination with dexmedetomidine or medetomidine and submitted to ovariohysterectomy. Methods: Twenty bitches pretreated with levomedetomidine and buprenorphine were anesthetized with $5 \mathrm{mg} . \mathrm{kg}^{-1}$ ketamine and $0.2 \mathrm{mg} \cdot \mathrm{kg}^{-1}$ midazolam i.v. Continuous infusion of $0.4 \mathrm{mg} . \mathrm{kg}^{-1} \cdot \mathrm{h}^{-1}$ midazolam and $20 \mathrm{mg} \cdot \mathrm{kg}^{-1} \cdot \mathrm{h}^{-1} \mathrm{ketamine}$ was initiated in combination with DEX $(\mathrm{n}=10): 20 \mu \mathrm{g} \cdot \mathrm{kg}^{-1} \cdot \mathrm{h}^{-1}$ dexmedetomidine or MED ( $\left.\mathrm{n}=10\right)$ : $30 \mu \mathrm{g} \cdot \mathrm{kg}^{-1} \cdot \mathrm{h}^{-1}$ medetomidine over 30 minutes. A pharmacokinetic study provided dexmedetomidine plasma concentration, set to be 3.0 ng. $\mathrm{mL}^{-1}$. Results: BIS decreased in both groups $(\mathrm{P}<0.05)$, but it was lower in $\mathrm{DEX}(\mathrm{P}<0.05)$ as compared to MED. No differences were found in hemodynamic parameters (heart rate, systolic, diastolic and mean arterial pressure) between groups ( $\mathrm{P}>0.05)$, but heart rate decreased in both groups, as compared to control values $(\mathrm{P}<0.05)$. Respiratory rate decreased $(\mathrm{P}<0.05)$ and expired end tidal $\mathrm{CO}{ }_{2}$ increased progressively $(\mathrm{P}<0.05)$ and similarly in both groups. Anesthetic recovery period was similar between groups $(\mathrm{P}<0.05)$ with no adverse effects. Conclusion: Continuous administration of dexmedetomidine with calculated plasma concentration equal to 3 ng. $\mathrm{mL}^{-1}$ in combination with midazolam and ketamine provides suitable anesthesia for spay surgery in bitches, hemodynamic stability and calm awakening with no adverse effects.
\end{abstract}

Key words: Anesthesia. Dexmedetomidine. Medetomidine. Dogs.

\section{RESUMO}

Objetivo: Verificar o comportamento hemodinâmico e o índice bispectral de cadelas anestesiadas com cetamina e midazolam associados à dexmedetomidina ou medetomidina. Métodos: Vinte cadelas receberam pré-tratamento com levomepromazina e buprenorfina e foram anestesiadas com cetamina, $5 \mathrm{mg} \cdot \mathrm{kg}^{-1}$ i.v., e midazolam, $0,2 \mathrm{mg} . \mathrm{kg}^{-1}$ i.v., seguidos da administração contínua de midazolam, 0,4 $\mathrm{mg} \cdot \mathrm{kg}^{-1} \cdot \mathrm{h}^{-1}$, e cetamina, $20 \mathrm{mg} \cdot \mathrm{kg}^{-1} \cdot \mathrm{h}^{-1}$, associados, conforme o grupo, à: DEX (n=10): dexmedetomidina $20 \mu \mathrm{g} \cdot \mathrm{kg}^{-1} \cdot \mathrm{h}^{-1} \mathrm{ou} \mathrm{MED}(\mathrm{n}=10)$ : medetomidina $30 \mu \mathrm{g} \cdot \mathrm{kg}^{-1} \cdot \mathrm{h}^{-1}$, mantidos por 30 minutos. A dose de dexmedetomidina foi obtida por meio de estudo farmacocinético planejando-se concentração plasmática de 3,0 ng. $\mathrm{mL}^{-1}$. Resultados: Os valores do BIS diminuíram em ambos os grupos (P<0,05), mas foram menores no grupo $\operatorname{DEX}(\mathrm{P}<0,05)$, em comparação com o grupo MED. Não houve diferença significativa nos atributos hemodinâmicos (frequência cardíaca, pressão arterial sistólica, diastólica e média) entre os grupos, mas a frequência cardíaca diminuiu em ambos os grupos em relação ao momento controle $(\mathrm{P}<0,05)$. A frequência respiratória diminuiu $(\mathrm{P}<0,05)$ e o $\mathrm{CO}_{2}$ expirado aumentou progressivamente em ambos os grupos $(\mathrm{P}<0,05)$. O tempo de recuperação anestésica foi semelhante entre os grupos $(\mathrm{P}>0,05)$, sem a presença de efeitos adversos. Conclusão: A administração contínua de dexmedetomidina em concentração plasmática calculada de 3 ng. $\mathrm{mL}^{-1}$, em combinação com midazolam e cetamina, resulta em plano anestésico adequado para castração de cadelas, estabilidade hemodinâmica e despertar tranquilo, sem efeitos adversos.

Descritores: Anestesia. Dexmedetomidina. Medetomidina. Cães.

${ }^{1}$ Research performed at Laboratory of Veterinary Anesthesiology, Department of Veterinary Surgery and Anesthesiology, School of Veterinary Medicine and Animal Science, Sao Paulo State University (UNESP), Botucatú, Brazil. 


\section{Introduction}

The combination of dissociative/sedative drugs in veterinary anesthesia has practical applications but its administration as a single dose may be inefficient. Based on this fact, a combination of different agents by continuous venous infusion has been suggested, especially drugs with a higher specificity for $\alpha_{2}$-receptors. The administration of anesthetic agents by continuous venous infusion reduces oscillations in their plasma concentration, the risk of over or under dosing and decreases total anesthetic agents consumption. Some commonly used drugs, such as xylazine and medetomidine, may cause adverse hemodynamic effects when administered as a bolus, while the administration by continuous infusion provides good cardiovascular stability ${ }^{1,2}$.

Dexmedetomidine, the pharmacologically active isomer of medetomidine, has been used in continuous infusion during anesthetic and surgical procedures in humans. Its usage in veterinary needs further investigation, since it is predominantly used as a single-bolus dose $\mathrm{e}^{3}$. The distribution and the elimination half-life of dexmedetomidine are 6 minutes and 2 hours, respectively. Latent period of dexmedetomidine is approximately 10 minutes and the mean-effective time is about 4 hours after a single injection. These values are similar to those found for medetomidine whose elimination half-life is 1 hour and latent period and analgesia are 10 to 20 minutes. Similarly to medetomidine, dexmedetomidine is highly lipophilic and has high selectivity for $\alpha_{2}$ adrenergic receptors ${ }^{4}$.

Dexmedetomidine promotes vasoconstriction in vascular smooth muscles. In the central nervous system (CNS), it causes sedation, anxiolysis and analgesia mediated by stimulation of $\alpha_{2}$-receptors in the locus coeruleus. In addition, an inhibition of the sympathetic efflux and a progressive reduction in circulating catecholamine levels are observed, which enhances parasympathetic activity. In general, the effects of dexmedetomidine on the cardiovascular system are reduction in heart rate with a diverse response in arterial pressure, depending on the dosage and animal species. In dogs, intravenous administration of dexmedetomidine causes a decrease in heart rate and an increase in systemic vascular resistance ${ }^{5}$. Its sedative and analgesic effects are higher than those of levomedetomidine, the other optical enantiomer of medetomidine 4 . A reduction of more than $95 \%$ of minimal alveolar concentration (MAC) of halothane is observed following intravenous administration of dexmedetomidine, which shows this drug may induce anesthetic state if administered alone ${ }^{6}$.

The combination of medetomidine and ketamine with midazolam administered via continuous infusion was found to provide hypnosis and cardiovascular stability required for laparotomy surgeries in female dogs pretreated with levomepromazine and buprenorphine ${ }^{2}$. The effect of that combination, replacing medetomidine with dexmedetomidine, which has a pharmacokinetic profile suitable for use in continuous infusion and prominent sedative effect, has not been reported yet.

This study investigated the hypothesis that the association of dexmedetomidine with ketamine and midazolam administered via continuous infusion would provide hypnosis and cardiovascular stability required for surgical procedures, similar to those reported in studies using medetomidine. Therefore, the objective of this study was to evaluate hemodynamics and bispectral index (BIS) values in female dogs pretreated with levomedetomidine and buprenorphine and anesthetized with ketamine and midazolam in combination with dexmedetomidine or medetomidine for ovariohysterectomy.

\section{Methods}

A total of 20 female dogs aged 1 to 3 years old, and weighing 7 to $15 \mathrm{~kg}$ were used in the experiment. For physiological homogeneity, animal selection was performed based on clinical and laboratorial evaluation (complete blood count, blood urea nitrogen and creatinine). The study was given the approval of the Institutional Ethical Committee and a signed written informed consent was obtained from all dog owners.

After 12 hour-food and 4 hour-water fast, animals were weighed and the following regions were shaved: frontotemporal skull in order to apply the BIS monitor, left pelvic member to insert the venous catheter and the region of the surgical incision. The animals were then randomly allocated to groups, anesthetized and underwent ovariohysterectomy.

After a $20 \mathrm{G}$ catheter insertion into the cephalic vein and initial administration of lactated Ringer's solution, $10 \mathrm{~mL} \cdot \mathrm{kg}^{-1} \cdot \mathrm{h}^{-1}$ (LF 2001 infusion pump; Lifemed ${ }^{\circledR}$, Sao Paulo, SP, Brazil), BIS electrodes were placed on the head of the animals. A cuff was then placed on the left thoracic limb for non-invasive arterial pressure measurement; electrodes for electrocardiography (DII) were placed on the thorax, and the anesthetic procedure, consisting of administration of preanesthetic medication intravenously with levomepromazine $\left(1 \mathrm{mg} \cdot \mathrm{kg}^{-1}\right)$ and buprenorphine $\left(3 \mu \mathrm{g} \cdot \mathrm{kg}^{-1}\right)$, was initiated. After 15 minutes, anesthesia was induced intravenously by bolus administration of $5 \mathrm{mg} \cdot \mathrm{kg}^{-1}$ ketamine in combination with $0.2 \mathrm{mg} . \mathrm{kg}^{-1}$ midazolam during 120 seconds. Continuous infusion of $0.4 \mathrm{mg} \cdot \mathrm{kg}^{-1} \cdot \mathrm{h}^{-1}$ midazolam and $20 \mathrm{mg} \cdot \mathrm{kg}^{-1} \cdot \mathrm{h}^{-1}$ ketamine was then immediately initiated in combination with dexmedetomidine $\left(20 \mu \mathrm{g} \cdot \mathrm{kg}^{-1} \cdot \mathrm{h}^{-1}\right)$ (DEX group) or medetomidine $\left(30 \mu \mathrm{g} \cdot \mathrm{kg}^{-1} \cdot \mathrm{h}^{-1}\right)$ (MED group) (infusion pump Anne, Abbott, Abbott Park, IL, USA). Infusion was interrupted after 30 minutes. After the induction of anesthesia and with the animals in recumbent position, tracheal intubation was performed and the animals remained in spontaneous ventilation through a $\mathrm{T}$ tube with oxygen enriched air in a flow of $20 \mathrm{~mL} \cdot \mathrm{kg}^{-1} \cdot \mathrm{min}^{-1}$.

Dexmedetomidine dose was determined based on a series of pharmacokinetic studies using the Stanpump ${ }^{\circledR}$ program (Figure 1). The program simulates plasma concentration profiles of the drug related to pharmacokinetic parameters previously studied according to the species ${ }^{7}$. The target plasma concentration of dexmedetomidine at the time of evisceration was set to be approximately $3.0 \mathrm{ng} \cdot \mathrm{mL}^{-1}$. This value was estimated according to studies in humans ${ }^{6}$. 


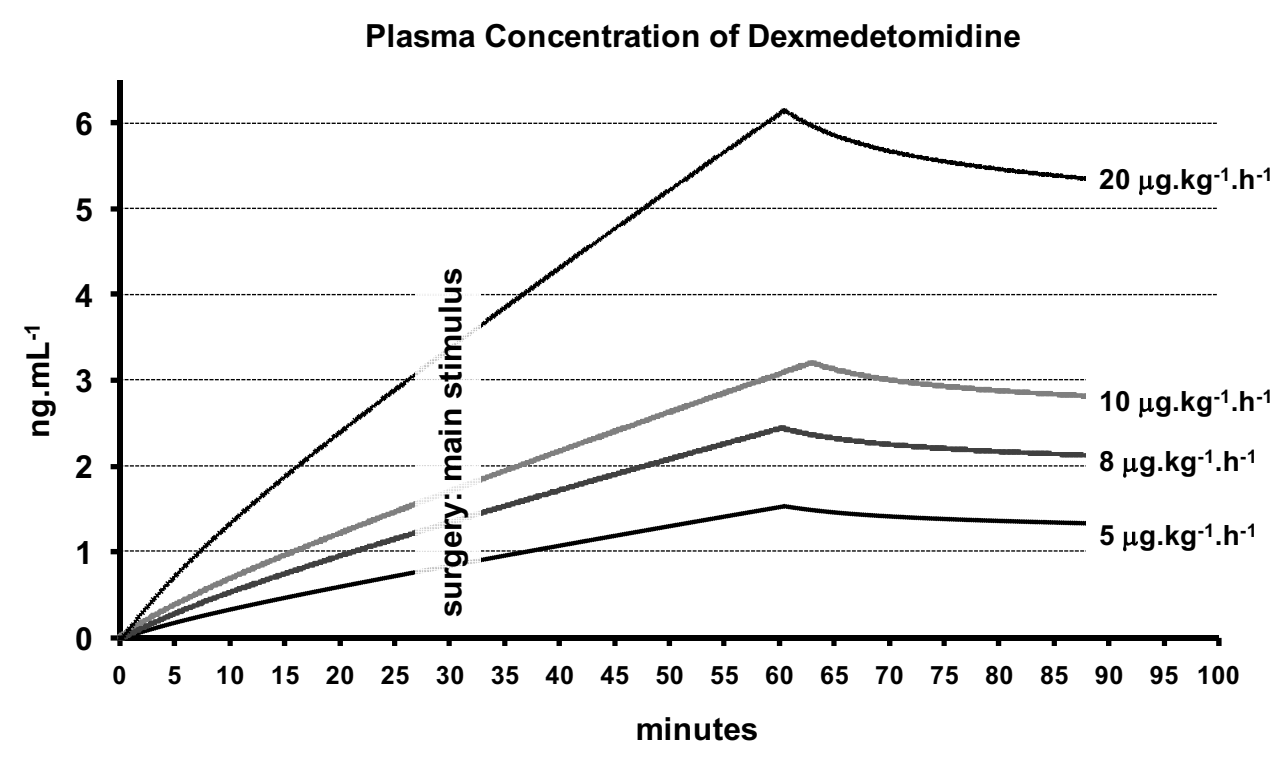

FIGURE 1 - Pharmacokinetic study of dexmedetomidine in dogs using the Stanpump ${ }^{\circledR}$ Program

Parameters were registered before venous catheterization and administration of preanesthetic medication (control: M0'), 15 minutes after administration of preanesthetic medication, i.e. immediately before anesthetic induction (M15') and every 10 minutes until the end of the drug administration (M25', M35' and M45', consecutively). Traction, clamping, and evisceration were performed between M25' and M35' time periods of observation.

The following parameters were monitored and registered: hemodynamic parameters - heart rate (HR), non invasive systolic arterial pressure (SAP), mean arterial pressure (MAP), and diastolic arterial pressure (DAP) (Ultracare SLP Monitor, SpaceLabs Medical, Washington, USA); Anesthetic depth parameters bispectral index (BIS) and electromyography (EMG) (A2000 BIS Monitoring System, Norwood, USA); Respiratory and oxygenation parameters- respiratory rate $(\mathrm{RR})$, tidal volume $\left(\mathrm{V}_{\mathrm{T}}\right)$, minute volume $\left(\mathrm{V}_{\mathrm{M}}\right)$, expired end tidal $\mathrm{CO}_{2}\left(\mathrm{ETCO}_{2}\right)$, pulse oximetry $\left(\mathrm{SpO}_{2}\right)$ (Capnomac Ultima, Datex-Ohmeda, Helsinki, Finland); and rectal temperature (Ultracare SLP Monitor, SpaceLabs Medical). Recovery period extended from the end of continuous infusion to resumption of quadruped position spontaneously.

Animals received a single dose of benzathine penicillin (40.000 I.U. $\left.\mathrm{kg}^{-1}\right)$ and analgesia with meloxicam (0.2 mg. $\left.\mathrm{kg}^{-1}\right)$ postoperatively. The latter was also prescribed during the 3 following days. The owners were advised to contact the researcher in case of adverse behavior or clinical signs of apathy.

Analysis of variance (ANOVA) was used to compare means of each variable at different observation times, followed by Tukey test for multiple comparisons. Student's t-test for independent samples was used to compare times of anesthetic recovery. Significance level was 5\%.

\section{Results}

Hemodynamic parameters (HR, SAP, MAP, DAP)

Heart rate reduced significantly in both groups $(\mathrm{P}<0.05)$ after administration of preanesthetic medication. Values were lower than those of control until the end of the procedure with no significant differences between groups $(\mathrm{P}>0.05)$ (Table 1). One animal from MED group had a second degree atrioventricular block after induction of anesthesia, which was an isolated event and disappeared spontaneously. No significant difference was observed in SAP, MAP and DAP at the observation times, neither between groups $(\mathrm{P}>0.05)$ (Table 1$)$. 
TABLE 1 - Hemodynamic parameters of dexmedetomidine group (DEX) and medetomidine group (MED) at the observation times

\begin{tabular}{|c|c|c|c|c|c|}
\hline \multirow[b]{2}{*}{ Variables } & \multirow[b]{2}{*}{ Control } & \multirow{2}{*}{$\begin{array}{l}15 \text { min after } \\
\text { premedication }\end{array}$} & $10 \mathrm{~min}$ & $20 \mathrm{~min}$ & 30min \\
\hline & & & \multicolumn{3}{|c|}{ After induction of anesthesia } \\
\hline \multicolumn{6}{|c|}{ Respiratory Rate (incursions.min ${ }^{-1}$ ) } \\
\hline DEX & $27 \pm 7$ & $23 \pm 9^{*}$ & $11 \pm 6^{*}$ & $12 \pm 6^{* \#}$ & $13 \pm 6^{*}$ \\
\hline MED & $27 \pm 9$ & $17 \pm 7^{*}$ & $18 \pm 10^{*}$ & $21 \pm 12$ & $20 \pm 9$ \\
\hline
\end{tabular}

Tidal Volume (mL.kg $\left.{ }^{-1}\right)$

\begin{tabular}{cccccc}
\hline DEX & $17.3 \pm 7.0$ & $11.2 \pm 3.3^{\#}$ & $12.9 \pm 5.6$ & $9.1 \pm 4.0^{* \#}$ & $9.9 \pm 3.4^{*}$ \\
MED & $19.0 \pm 4.4$ & $18.6 \pm 5.2$ & $14.0 \pm 6.4$ & $15.0 \pm 4.3$ & $11.2 \pm 2.6$ \\
\hline
\end{tabular}

Minute Volume (mL.kg $\left.{ }^{-1} \cdot \mathrm{min}^{-1}\right)$

\begin{tabular}{cccccc}
\hline DEX & $470 \pm 236$ & $234 \pm 67$ & $132 \pm 86^{*}$ & $100 \pm 46^{* \#}$ & $121 \pm 43^{* \#}$ \\
MED & $545 \pm 138$ & $311 \pm 89$ & $290 \pm 257^{*}$ & $332 \pm 172$ & $214 \pm 88^{*}$ \\
\hline
\end{tabular}

\section{Expired End Tidal $\mathrm{CO}_{2}\left(\mathrm{ETCO}_{2}\right)(\mathrm{mmHg})$}

\begin{tabular}{cccccc}
\hline DEX & $26.1 \pm 2.7$ & $21.4 \pm 5.0^{\#}$ & $39.2 \pm 13.5^{*}$ & $44.0 \pm 13.5^{*}$ & $49.3 \pm 13.5^{*}$ \\
MED & $30.3 \pm 4.9$ & $30.9 \pm 3.7$ & $37.4 \pm 7.4$ & $42.3 \pm 7.3^{*}$ & $42.0 \pm 3.3^{*}$ \\
\hline Pulse Oximetry (SpO $)(\%)$ & & & \\
\hline DEX & $97.7 \pm 0.7$ & $97.2 \pm 0.8$ & $98.3 \pm 1.1$ & $98.7 \pm 0.7$ & $98.8 \pm 0.4$ \\
MED & $97.6 \pm 1.2$ & $97.7 \pm 0.8$ & $97.6 \pm 1.9$ & $97.2 \pm 2.2$ & $97.2 \pm 2.8$ \\
\hline
\end{tabular}

$* \mathrm{P}<0.05$ : versus control at the same group; values as mean \pm standard deviation.

\section{Bispectral Index (BIS) and Electromyography (EMG)}

There was a slight reduction in BIS values after preanesthetic medication in both groups. After induction of anesthesia, significant lower BIS values were observed as compared to control in both groups $(\mathrm{P}<0.05)$. This reduction was progressive and similar in both groups. Significant lower values were observed in DEX group as compared to those in MED group after preanesthetic medication and 10 minutes after induction of anesthesia $(\mathrm{P}<0.05)$ (Figure 2). Values of EMG reduced significantly $(\mathrm{P}<0.05)$ and progressively from the induction of anesthesia to the end of the study, similarly in both groups. Only in the second time of observation, values of DEX group were significantly lower than those of MED group $(\mathrm{P}<0.05)$ (Figure 3). 


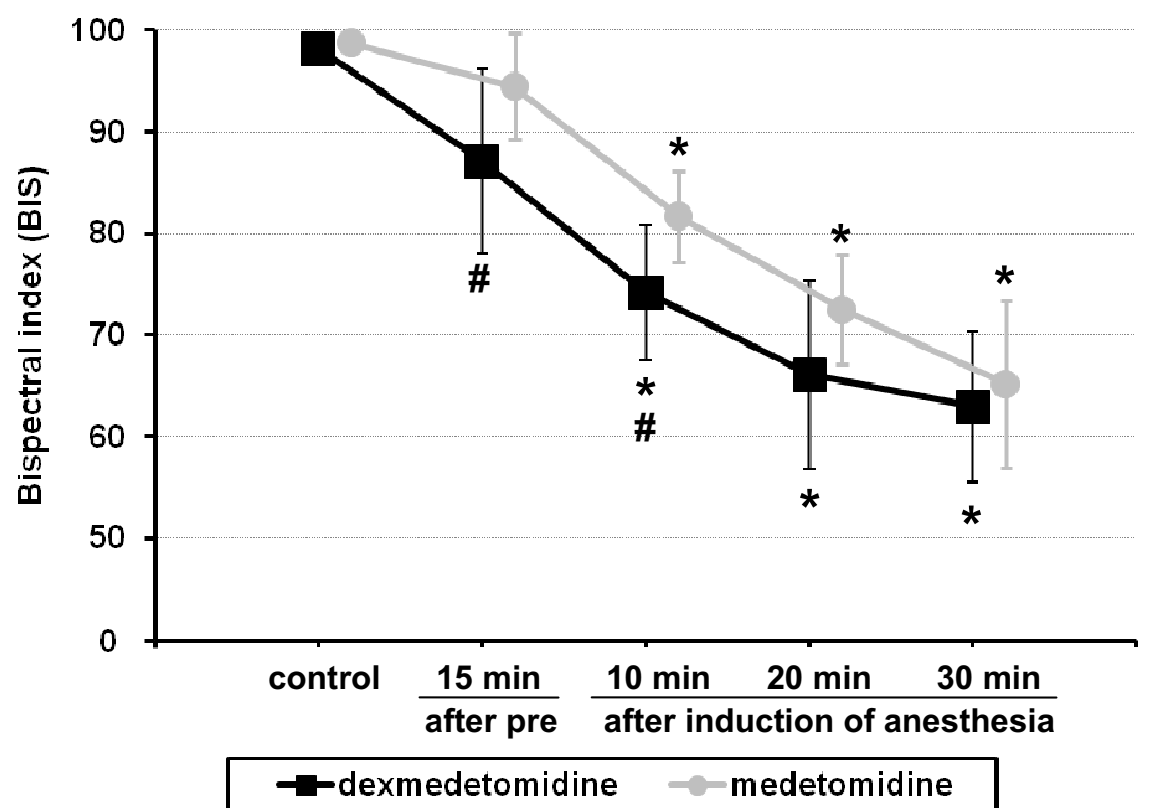

FIGURE 2 - Bispectral Index (BIS) of groups treated with dexmedetomidine (DEX) or medetomidine (MED) at the five time points

${ }^{*} \mathrm{P}<0.05$ : versus control at the same group; ${ }^{\#} \mathrm{P}<0.05$ : DEX versus MED at the same time of observation; values as mean \pm standard deviation; pre = preanesthetic medication.

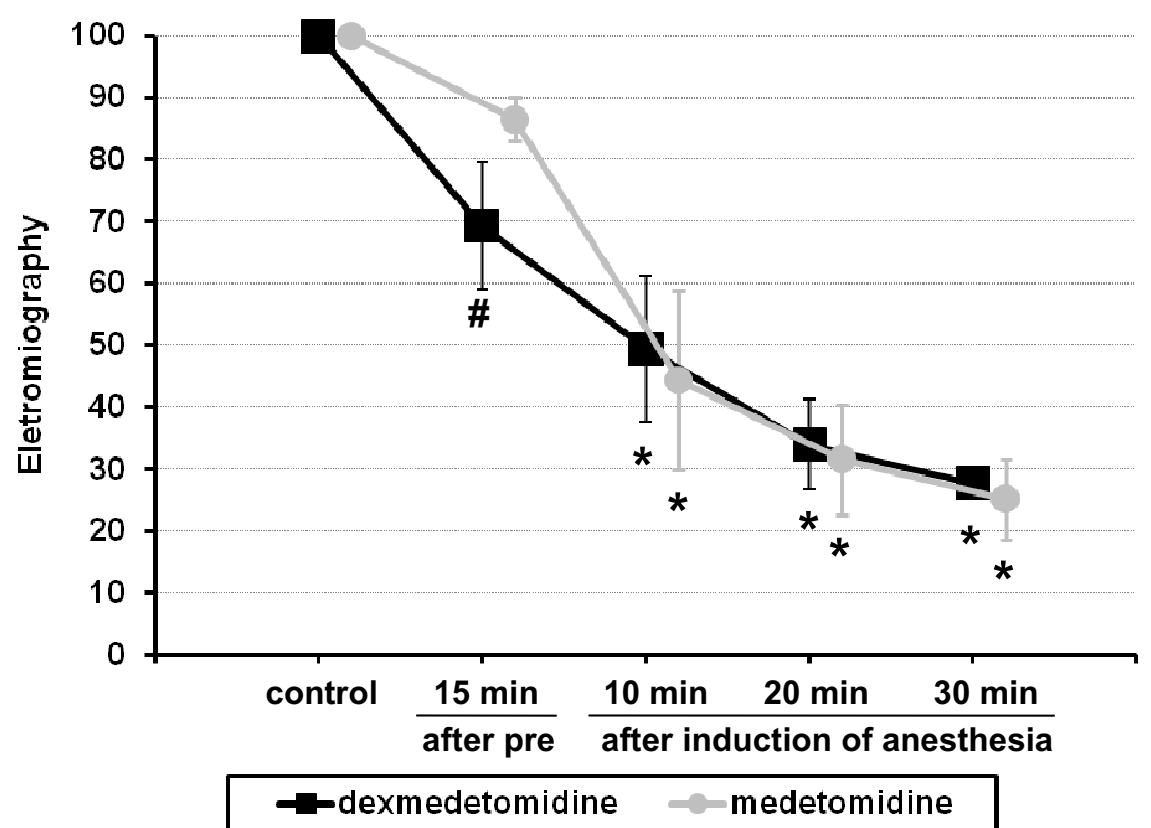

FIGURE 3 - Electromyography (EMG) of groups treated with dexmedetomidine (DEX) or medetomidine (MED) at the 5 times points

${ }^{*} \mathrm{P}<0.05$ : versus control at the same group; ${ }^{\#} \mathrm{P}<0.05$ : $\mathrm{DEX}$ versus $\mathrm{MED}$ at the same time of observation; values as mean \pm standard deviation; pre $=$ preanesthetic medication . 
Respiratory and oxygenation parameters $\left(R R, V_{T}, V_{M}\right.$ $\left.\mathrm{ETCO}_{2}, \mathrm{SpO}_{2}\right)$

There was a significant reduction in respiratory rate values as compared to control values $(\mathrm{P}<0.05)$ in both groups after preanesthetic medication. After induction of anesthesia, an additional reduction of respiratory rate was observed only in DEX group, and only after 20 minutes of induction of anesthesia, values of DEX group were significantly lower as compared to those of MED group $(\mathrm{P}<0.05)$ (Table 2$)$. Tidal volume decreased in both groups after preanesthetic medication and induction of anesthesia. A significant decrease in values of tidal volume was observed in the DEX group as compared to control values only in the last two time points $(\mathrm{P}<0.05)$. There was a statically significant difference between groups $(\mathrm{P}<0.05)$ after preanesthetic medication and 20 minutes after the induction of anesthesia, in which the values of DEX group were lower as compared to those of MED group (Table 2). Minute volume values were lower in both groups as compared to those of controls after preanesthetic medication and during anesthesia. This difference was statistically significant $(\mathrm{P}<0.05)$ at all time points during anesthesia in DEX group, and at 10 and 30 minutes after induction of anesthesia in MED group (Table 2). Values of $\mathrm{ETCO}_{2}$ increased progressively in both groups and this difference was statistically significant as compared to control values during all period of anesthesia. After preanesthetic medication, DEX group values were significantly higher than those observed in MED group $(\mathrm{P}<0.05)$ (Table 2). No significant difference in $\mathrm{SpO}_{2}$ between groups was found at any time point (Table 2).

TABLE 2 - Respiratory and Oxygenation Parameters of dexmedetomidine group (DEX) and medetomidine group (MED) at the times of observation

\begin{tabular}{|c|c|c|c|c|c|}
\hline & & 15 min after & $10 \mathrm{~min}$ & $20 \mathrm{~min}$ & 30min \\
\hline Variables & Control & premedication & \multicolumn{3}{|c|}{ After induction of anesthesia } \\
\hline \multicolumn{6}{|c|}{ Heart Rate (beats. min $^{-1}$ ) } \\
\hline DEX & $133 \pm 15$ & $106 \pm 24 *$ & $90 \pm 25^{*}$ & $98 \pm 36^{*}$ & $93 \pm 31 *$ \\
\hline MED & $121 \pm 23$ & $107 \pm 27^{*}$ & $99 \pm 25^{*}$ & $100 \pm 27 *$ & $99 \pm 25^{*}$ \\
\hline
\end{tabular}

Systolic Arterial Pressure (mmHg)

\begin{tabular}{cccccc}
\hline DEX & $114.8 \pm 14.7$ & $110.4 \pm 23.5$ & $111.3 \pm 24.2$ & $129.1 \pm 22.5$ & $125.3 \pm 20.1$ \\
MED & $125.6 \pm 20.3$ & $114.5 \pm 14.5$ & $119.3 \pm 12.2$ & $123.8 \pm 18.6$ & $120.1 \pm 16.8$ \\
\hline
\end{tabular}

\section{Mean Arterial Pressure ( $\mathrm{mmHg})$}

\begin{tabular}{cccccc}
\hline DEX & $97.5 \pm 8.9$ & $84.3 \pm 18.3$ & $98.6 \pm 25.2$ & $112.1 \pm 20.9$ & $106.5 \pm 15.8$ \\
MED & $105.6 \pm 18.1$ & $93.0 \pm 11.6$ & $100.7 \pm 15.4$ & $104.5 \pm 16.0$ & $99.9 \pm 14.9$ \\
\hline \multicolumn{7}{l}{ Diastolic Arterial Pressure (mmHg) } & & & \\
\hline DEX & $84.7 \pm 7.6$ & $70.4 \pm 14.8$ & $85.0 \pm 24.3$ & $96.8 \pm 26.6$ & $92.3 \pm 21.8$ \\
MED & $91.6 \pm 17.6$ & $74.8 \pm 11.2$ & $91.3 \pm 16.4$ & $94.3 \pm 19.5$ & $89.5 \pm 15.7$ \\
\hline
\end{tabular}

$* \mathrm{P}<0.05$ : versus control at the same group; $\# \mathrm{P}<0.05$ : DEX versus $\mathrm{MED}$ at the same time; values as mean \pm standard deviation; pre $=$ preanesthetic medication. 


\section{Body temperature}

A decrease of about one degree Celsius in body temperature was found at the observation times in both groups, but with no statistically significant difference $(\mathrm{P}>0.05)$. No statis- tically significant difference in body temperature was observed between groups $(\mathrm{P}>0.05)$ (Table 3$)$.

TABLE 3 - Rectal temperature of dexmedetomidine group (DEX) and medetomidine group (MED) at the times of observation.

\begin{tabular}{|c|c|c|c|c|c|}
\hline & & 15 min after & $10 \mathrm{~min}$ & $20 \mathrm{~min}$ & 30min \\
\hline Variables & Control & premedication & \multicolumn{3}{|c|}{ After induction of anesthesia } \\
\hline \multicolumn{6}{|c|}{ Temperature $\left({ }^{\circ} \mathrm{C}\right)$} \\
\hline DEX & $38.8 \pm 0.4$ & $38.8 \pm 0.5$ & $38.0 \pm 0.6$ & $37.7 \pm 0.5$ & $37.7 \pm 0.5$ \\
\hline MED & $37.4 \pm 0.5$ & $37.2 \pm 0.7$ & $36.7 \pm 0.9$ & $36.6 \pm 0.8$ & $36.4 \pm 0.8$ \\
\hline
\end{tabular}

Values as mean \pm standard deviation.

\section{Anesthetic recovery}

Average time (mean \pm standard deviation) for extubation was $16.7 \pm 2.1$ minutes for DEX group and $15.0 \pm 1.9$ for MED group $(\mathrm{P}<0.05)$. Also, average time (mean \pm standard deviation) for animals to come back to quadruped position was similar between groups, $51.4 \pm 5.5$ minutes and $48.3 \pm 5.1$ minutes for DEX group and MED group, respectively $(\mathrm{P}<0.05)$. No other adverse effects (tremor, vocalization or salivation) were observed and no dog owner made contact with the responsible for the research after hospital discharge.

\section{Discussion}

Dexmedetomidine, a drug that only recently has been used as veterinary anesthetic, was compared to medetomidine, which proved to be an effective anesthetic when combined with midazolam for spaying of female $\operatorname{dog} s^{2}$. In this research, hemodynamic variables of female dogs anesthetized with ketamine and midazolam combined with dexmedetomidine or medetomidine after preanesthetic medication (levomepromazine and buprenorphine) for ovariohysterectomy were studied. Bispectral index and electromyography as well as respiratory parameters were evaluated. In order to adjust plasma concentration of dexmedetomidine according to the surgical procedure, a pharmacokinetic study was developed using the Stanpump ${ }^{\circledR}$ program, so that the plasma concentration of dexmedetomidine at the moment of traction and evisceration was about $3 \mathrm{ng} \cdot \mathrm{mL}^{-1}$. This concentration causes a significant decrease in pain scores as well as deep sedation in humans when used as a sole agent ${ }^{6}$.

The hypothesis of this study was that dexmedetomidine, combined with ketamine and midazolam and administered by continuous infusion in female dogs pretreated with levomepromazine and buprenorphine, would provide conditions of hypnosis and cardiovascular stability required for laparotomy and spay surgery.
The typical hemodynamic response with the use of $\alpha_{2}$-agonists includes increased arterial pressure in different degrees and decreased heart rate mediated mainly by baroreflex. Decreased heart rate is also due to a decrease in sympathetic activity by inhibition of noradrenaline release from sympathetic nerves and noradrenergic neurons in the CNS. The intensity of cardiovascular manifestations after the administration of dexmedetomidine depends on the dose ${ }^{6}$, via of administration, the combination of drugs, surgical procedure ${ }^{5}$, and distribution of $\alpha_{2}$ receptors, according to the animal species ${ }^{8}$. After administration of dexmedetomidine, a characteristic biphasic response of arterial pressure is also expected, that is an initial increase followed by a decrease, partly due to activity of $\alpha_{1}$ receptors and partly to post-junctional $\alpha_{2}$ receptors. Increasing doses of dexmedetomidine lead to an increase in arterial pressure ${ }^{6}$.

In the present research, dexmedetomidine decreased heart rate to clinically acceptable values without any other alterations in cardiac rhythm. Dexmedetomidine led to a small increase in arterial pressure as compared to control values, however such increase was not statistically significant and was considered clinically acceptable. Lin et al. ${ }^{9}$, in a study on hemodynamic effects and tissue perfusion of dexmedetomidine administered over 24 hours in dogs, reported a higher reduction in heart rate and a significant increase in mean arterial pressure with plasma values of dexmedetomidine lower than those used in the present research. As there are many possible anesthetic drug combinations, it may be difficult to compare the results of the present study with others from the literature. The use of both dexmedetomidine and medetomidine combined with midazolam and ketamine resulted in good control of hemodynamic parameters, which are similar to those reported by other authors when such drugs were administered intramuscularly. However, the administration of levomedetomidine before dexmedetomidine may worsen bradycardia caused by dexmedetomidine ${ }^{10}$ and the administration of atropine before 
dexmedetomidine prevents bradycardia, but leads to arterial hypertension ${ }^{11}$.

In the present study, dexmedetomidine resulted in cardiovascular stability similar to that from medetomidine, as previously observed by the same research group ${ }^{2}$. One patient had a first degree atrioventricular block following administration of medetomidine, with no hemodynamic compromise. In a study on cardiovascular effects of dexmedetomidine (doses of 10 and $\left.20 \mu \mathrm{g} \cdot \mathrm{kg}^{-1}\right)$ in comparison with medetomidine $\left(40 \mu \mathrm{g} \cdot \mathrm{kg}^{-1}\right)$, Kuusela et al. ${ }^{10}$ reported similar cardiovascular responses and a slightly deeper sedation with the administration of dexmedetomidine.

The doses of both $\alpha_{2}$-agonists used in this study along with the continuous administration technique did not result in a significant increase in arterial pressure expected due to a possible synergetic effect of ketamine. High arterial pressure values have been observed in pigs with higher doses of $\alpha_{2}$-agonists via bolus and in combination with ketamine ${ }^{12}$. However, the combination of dexmedetomidine and ketamine has been shown to be hemodynamically safe and efficient in different animal species ${ }^{13}$.

After the beginning of continuous infusion of either dexmedetomidine or medetomidine, a substantial and continuous decrease in BIS was observed. This finding is similar to that observed with the administration of xylazine and medetomidine ${ }^{2}$. Dexmedetomidine administered by continuous infusion or even epidurally ${ }^{14}$ leads to a decrease in the BIS and has the ability to provide sedation similar to that of midazolam. Similar findings in electromyography were observed in the present study: a significant and progressive decrease of electromyography values at observation times and lower values in DEX group at the beginning of the procedure.

Nociceptive stimulation may lead to the wakening of a hypnotic state and provide a significant increase in BIS. In the present study, no alterations in BIS were observed at any time during surgery. Campagnol et al. ${ }^{14}$ reported an increase in BIS with the nociceptive stimulation after epidural administration of dexmedetomidine. Thus, the negative response to surgical stimulus may be related to the strategy used in this study, that is, the pharmacokinetic simulation to obtain plasma concentrations about $3 \mathrm{ng} \cdot \mathrm{mL}^{-1}$ at the moment of traction, clamping, and evisceration. Then, this value of dexmedetomidine plasma concentration along with the combination of drugs used in this study seems to be suitable for ovariohysterectomy.

Similarly to what was reported in rats, the electromyography decreased substantially and progressively right after the administration of medetomidine and dexmedetomidine, suppressing the cataleptoid state induced by ketamine $^{15}$. Such myorelaxation was also observed in a study with dogs, which compared the combination of dexmedetomidine and buprenorphine with butorphanol and diazepam ${ }^{16}$. In the present study, the reduction of EMG values was more prominent than that of BIS values. This finding has already been reported previously ${ }^{2}$.

The animals had good blood oxygenation in both groups, as verified by pulse oximetry. Respiratory rate decreased significantly in both groups, and values of DEX group were significantly lower than those of MED group during clamping and evisceration. Thus, a significant increase in $\mathrm{ETCO}_{2}$ was observed in both groups.
According to Groeben et al. ${ }^{17}$, dexmedetomidine does not significantly decrease respiratory rate or spontaneous ventilation, differently from what was found in the present study and also reported by Gómez-Villamandos et al. ${ }^{18}$ in a study on the effects of the combination of propofol and desflurane in dogs pretreated with different doses of dexmedetomidine. The ventilation with oxygen-enriched air during the administration of $\alpha_{2}$-agonists drugs greatly decreases the probability of hypoxia and cyanosis. Thus, patients sedated with dexmedetomidine must receive oxygen and undergo constant monitoring mainly during spontaneous ventilation.

Body temperature had a slight decrease in both groups, but with no significant difference or clinical relevance, similar to what was observed in another study on these drugs ${ }^{1}$.

In the present study, both the anesthetic recovery period and its characteristics were similar in both groups and also similar to what has been reported in the literature ${ }^{1,2}$.

One of the limitations of this study is the short infusion period of the proposed combinations, since the surgical procedure was performed in a short period of time. The continuous intravenous administration of anesthetic drugs with stable plasma concentrations would be very advantageous when their administration is required for a long time and mainly when plasma concentrations, as performed in this study, can be estimated by simulation. The pharmacokinetic study helped to avoid too many pilot studies.

\section{Conclusion}

Continuous administration of dexmedetomidine with target plasma concentration calculated from a pharmacokinetic simulation ( $\left.3 \mathrm{ng} . \mathrm{mL}^{-1}\right)$ in combination with midazolam and ketamine provides suitable anesthesia for ovariohysterectomy in dogs, verified by the adequate decrease in BIS. This technique of anesthesia also results in good hemodynamic stability as well as calm awakening without any adverse effects.

\section{References}

1. Santos GJ, Hatschbach E, Mattos Junior E, Massone F. Parametric evaluation of methotrimeprazine-midazolam-ketamine and methotrimeprazine-midazolam-ketamine-xylazine combination in dogs. Acta Cir Bras. 2006;21(5):304-9.

2. Silva FC, Hatschbach E, Lima AF, de Carvalho YK, Massone F. Continuous infusion in adult females dogs submitted to ovariohysterectomy with midazolam-xylazine and/or medetomidine pre-treated with methotrimeprazine and buprenorphine. Acta Cir Bras. 2007;22(4):272-8.

3. Kuusela E, Vainio O, Short CE, Leppaluoto J, Huttunen P, Ström S, Huju V, Valtonen A, Raekallio M. A comparison of propofol infusion and propofol/isoflurane anaesthesia in dexmedetomidine premedicated dogs. J Vet Pharmacol Ther. 2003;26(3):199-204.

4. Kuusela E, Raekallio M, Anttila M, Falck I, Molsa S, Vainio O. Clinical effects and pharmacokinetics of medetomidine and its enantiomers in dogs. J Vet Pharmacol Ther. 2000;23(1):15-20.

5. Braz LG, Braz JR, Castiglia YM, Vianna PT, Vane LA, Modolo NS, do Nascimento P Jr, da Silva AL, Kinsky MP. Dexmedetomidine alters the cardiovascular response during infra-renal aortic cross-clamping in sevoflurane-anesthetized dogs. J Invest Surg. 2008;21(6):360-8. 
6. Ebert TJ, Hall JE, Barney JA, Uhrich TD, Colinco MD. The effects of increasing plasma concentrations of dexmedetomidine in humans. Anesthesiology. 2000;93(2):382-94.

7. Shafer SL, Siegel LC, Cooke JE, Scott JC. Testing computer-controlled infusion pumps by simulation. Anesthesiology. 1988;68(2):261-6.

8. Civantos Calzada B, Aleixandre de Artinano A. Alpha-adrenoceptor subtypes. Pharmacol Res. 2001;44(3):195-208.

9. Lin GY, Robben JH, Murrell JC, Aspegren J, McKusick BC, Hellebrekers LJ. Dexmedetomidine constant rate infusion for 24 hours during and after propofol or isoflurane anaesthesia in dogs. Vet Anaesth Analg. 2008;35(2):141-53. 10. Kuusela E, Vainio O, Kaistinen A, Kobylin S, Raekallio M. Sedative, analgesic, and cardiovascular effects of levomedetomidine alone and in combination with dexmedetomidine in dogs. Am J Vet Res. 2001;62(4):616-21. 11. Alvaides RK, Neto FJ, Aguiar AJ, Campagnol D, Steagall PV. Sedative and cardiorespiratory effects of acepromazine or atropine given before dexmedetomidine in dogs. Vet Rec. 2008;162(26):852-6.

12. Vainio OM, Bloor BC, Kim C. Cardiovascular effects of a ketamine-medetomidine combination that produces deep sedation in Yucatan mini swine. Lab Anim Sci. 1992;42(6):582-8.

13. Selmi AL, Mendes GM, Figueiredo JP, Barbudo-Selmi GR, Lins BT. Comparison of medetomidine-ketamine and dexmedetomidine- ketamine anesthesia in golden-headed lion tamarins. Can Vet $\mathrm{J}$. 2004;45(6):481-5.

14. Campagnol D, Teixeira Neto FJ, Giordano T, Ferreira TH, Monteiro ER. Effects of epidural administration of dexmedetomidine on the minimum alveolar concentration of isoflurane in dogs. Am J Vet Res. 2007;68(12):1308-18.

15. Bol CJ, Vogelaar JP, Tang JP, Mandema JW. Quantification of pharmacodynamic interactions between dexmedetomidine and midazolam in the rat. J Pharmacol Exp Ther. 2000;294(1):347-55.

16. Leppanen MK, McKusick BC, Granholm MM, Westerholm FC, Tulamo R, Short CE. Clinical efficacy and safety of dexmedetomidine and buprenorphine, butorphanol or diazepam for canine hip radiography. J Small Anim Pract. 2006;47(11):663-9.

17. Groeben H, Mitzner W, Brown RH. Effects of the alpha2-adrenoceptor agonist dexmedetomidine on bronchoconstriction in dogs. Anesthesiology. 2004;100(2):359-63.

18. Gomez-Villamandos RJ, Palacios C, Benitez A, Granados MM, Dominguez JM, Lopez I, Ruiz I, Aguilera E, Santisteban JM. Dexmedetomidine or medetomidine premedication before propofoldesflurane anaesthesia in dogs. J Vet Pharmacol Ther. 2006;29(3):157-63.

\section{Correspondence:}

Paulo do Nascimento Jr

Department of Anesthesiology

Distrito de Rubião Junior, $\mathrm{S} / \mathrm{N}$

18.618-970 Botucatú - SP Brazil

pnasc@,fmb.unesp.br

\section{How to cite this article}

Silva FC, Hatschbach E, Carvalho YK, Minto BW, Massone F, Nascimento Junior P. Hemodynamics and bispectral index (BIS) of dogs anesthetized with midazolam and ketamine associated with medetomidine or dexmedetomidine and submitted to ovariohysterectomy. Acta Cir Bras. [serial on the Internet] 2010 Mar-Apr;25(2). Available from URL: http://www.scielo.br/acb 